\section{$\underset{\text { hommes }}{\text { \& migrations }}$}

\section{Hommes \& migrations}

Revue française de référence sur les dynamiques

migratoires

$1304 \mid 2013$

Frontières

\title{
Karine Tuil, L'Invention de nos vies,
}

Paris, Grasset, 2013, 493 p., 20,90€.

\section{Mustapha Harzoune}

\section{OpenEdition}

1 Journals

\section{Édition électronique}

URL : http://journals.openedition.org/hommesmigrations/2691

DOI : 10.4000/hommesmigrations.2691

ISSN : 2262-3353

\section{Éditeur}

Musée national de l'histoire de l'immigration

\section{Édition imprimée}

Date de publication : 1 octobre 2013

Pagination : 186-187

ISBN : 978-2-919040-24-7

ISSN : 1142-852X

Référence électronique

Mustapha Harzoune, "Karine Tuil, L'Invention de nos vies, », Hommes \& migrations [En ligne], $1304 \mid$

2013, mis en ligne le 20 mars 2014, consulté le 22 septembre 2020. URL : http://

journals.openedition.org/hommesmigrations/2691; DOI : https://doi.org/10.4000/

hommesmigrations.2691

Ce document a été généré automatiquement le 22 septembre 2020.

Tous droits réservés 


\title{
Karine Tuil, L'Invention de nos vies,
}

\author{
Paris, Grasset, 2013, 493 p., 20,90€.
}

\section{Mustapha Harzoune}

\section{RÉFÉRENCE}

Karine Tuil, L'Invention de nos vies, Paris, Grasset, 2013, 493 p., 20,90€.

1 “Avec le mensonge on peut aller très loin, mais on ne peut jamais en revenir", dit un proverbe juif qui illustre et ramasse les 493 pages de ce roman. L'Invention de nos vies est un titre trompeur. Il pourrait laisser croire que nous sommes maîtres de nos existences, capables d'en tracer les trajectoires et les contours, de nous défaire des chaînes qui nous relient aux piquets des communautés et des déterminations sociales, de nous exonérer du dédale des psychologies, de nous abstraire des logiques identitaires. Pourtant, ce roman protéiforme montre que quelles que soient la longueur de la laisse et les marges de liberté prises, chacun est ramené à son piquet. Les enfermements identitaires, les distinctions de classe, le poids des héritages semblent se jouer des libertés individuelles.

2 Samir Tahar, brillantissime étudiant en droit, disposant d'un CV exceptionnel, blackboulé pourtant par tous les cabinets d'avocats de renom, décide de prendre quelques libertés avec ses origines. Un petit arrangement sans conséquences a priori. Deux lettres supprimées sur son CV et il devient Sam. Sam comme Samir, bien sûr, mais aussi - pourquoi pas ? - comme Sami ou même Samuel. L'arrangement se transformera en mensonge et Samir en richissime et influent avocat new-yorkais, pratiquant le shabbat et la cacherout, pataugeant dans la crème juive de Manhattan. Le rejeton d'un couple d'immigrés tunisiens épousera même la convoitée Ruth, l'héritière d'une des plus grosses fortunes américaines, fille de la très puissante et religieuse famille Berg, dont le grand-père servit dans les rangs de l'Irgoun... L'aller sera sans retour.

3 Samir sera rattrapé non par ses turpitudes sexuelles mais par un demi-frère, François Yahyaoui devenu, lui, après sa conversion, Djamel. Parti en Afghanistan rejoindre ses pseudo-frangins en humanité, en religion et en djihad, il sera cueilli par la soldatesque 
étatsunienne et expédié fissa à Guantanamo. Le lien entre François/Djamel et Samir/ Sam sera vite fait et le début de la fin commence pour Samir.

4 Une partie de l'imposture biographique de Samir est empruntée à la vie de son meilleur ami, Samuel, juif laïcard, écrivain raté qui a échoué dans une minable banlieue parisienne. Tandis que son Arabe de copain se prélasse sur les sommets, lui, l'éducateur de cité, se morfond dans son trou et se pose en victime incomprise. Sa seule réussite, son seul réconfort, est de partager sa vie avec l'irrésistible Nina qui, quelque vingt ans plus tôt, a décidé de rester avec le fragile Samuel plutôt que de partir avec le flamboyant Samir.

5 La caméra plonge, circule, s'arrête, scrute, accélère... Malgré quelques répétitions, le lecteur-spectateur est embarqué dans un récit maîtrisé à la perfection. Pour autant, ce livre captivant grossit, ici ou là, le trait, sans doute pour les besoins de la démonstration ou de la réflexion, mais cela se traduit aussi par une addition de clichés sur les Arabes ou la banlieue renvoyée à la violence, aux tournantes, à l'antisémitisme, au sexisme, à l'enfermement religieux. Quant à Samir, il reste un Arabe du ressentiment, un jouisseur sexuel insatiable qui mène une double vie, version romancée de la polygamie: épouse juive bon teint, enfants obéissants et dociles, d'un côté, maîtresse entretenue, de l'autre.

6 Deux autres thèmes traversent le roman : celui de la création littéraire avec Samuel et celui de l'injonction sociétale de performance, de réussite, de domination, de supériorité. Et si L'Invention de nos vies consistait d'abord à se libérer de ces injonctions carnassières? Comme Nina. Comme Samuel. Et peut-être comme Samir. 